\title{
The Case of MRI Repetitions with Direct and Indirect Cost Implications: Evidence from Hacettepe University Hospitals'
}

\begin{abstract}
Dilek BASSAR (https://orcid.org/0000-0001-6501-8760), Department of Economics, Hacettepe University; Hacettepe University Health Economics and Health Policy Research and Application Center, Turkey; e-mail: dbasar@hacettepe.edu.tr
\end{abstract}

İlhan Can ÖZEN (https://orcid.org/0000-0003-0524-5536), Department of Economics, Middle East Technical University, Turkey; e-mail: iozen@metu.edu.tr

Selcen ÖZTÜRK (https://orcid.org/0000-0003-2011-2360), Department of Economics, Hacettepe University; Hacettepe University Health Economics and Health Policy Research and Application Center, Turkey; e-mail: selcen@hacettepe.edu.tr

Ekim GÜMELER (https://orcid.org/0000-0003-3783-2372), Department of Radiology, Hacettepe University, Turkey; e-mail: ekimgumeler@gmail.com

Deniz AKATA (https://orcid.org/0000-0002-1318-0085), Department of Radiology, Hacettepe University, Turkey; e-mail:dakata@hacettepe.edu.tr

Arbay Özden ÇїFÇ̇ं (https://orcid.org/0000-0001-9226-764X), Department of Pediatric Surgery, Hacettepe University; Hacettepe University Health Economics and Health Policy Research and Application Center, Turkey; e-mail: arbay@hacettepe.edu.tr

\section{Tekrarlanan MR Görüntülemelerinin Doğrudan ve Dolaylı Maliyet Etkileri: Hacettepe Üniversitesi Hastanelerinden Bulgular ${ }^{2}$}

\begin{abstract}
This study investigates the case of repeated MRIs using data from Hacettepe University Hospitals. Results indicate that almost $34 \%$ of MRI consultations have to be repeated within the same year due to suboptimal quality that hinders correct assessment and diagnosis. Suboptimal quality refers to; movement artefacts, use of wrong scan technique or sequence, inexperienced reader and/or shortened time intervals. In fact, almost $30 \%$ of those repetitions result in a change in diagnosis. Results suggest that the probability of repetition is higher among women and children.

Keywords

$$
\text { Health Policy, MRI Overutilization, Direct and Indirect Costs, }
$$
Turkey.

JEL Classification Codes : $\quad$ I18, H51, H75.

$$
\text { Öz }
$$

Bu çalışma Hacettepe Üniversitesi Hastanelerinden elde edilen veriler aracıllı̆ıyla tekrarlanan MR incelemelerini araştırmaktadır. Çalışmadan elde edilen sonuçlar konsülte edilen MR'ların yaklaşık \%34'ünün düşük kalite sebebiyle aynı yıl içinde tekrar edildiğini göstermiştir. Düşük kalite; hareket artefaktları, yanlış tarama tekniği veya dizisinin kullanımı, deneyimsiz okuyucu ve / veya kısaltılmış zaman aralıkları olarak tanımlanmaktadır. Söz konusu MR'ların \%30'unda ise tanı değişikliği
\end{abstract}


Başar, D. \& İ.C. Özen \& S. Öztürk \& E. Gümeler \& D. Akata \& A.Ö. Çiftçi (2019), "The Case of MRI Repetitions with

Direct and Indirect Cost Implications: Evidence from Hacettepe University Hospitals", Sosyoekonomi, Vol. 27(41), $253-262$.

olmuştur. Sonuçlar çocuklar ve kadınlar için tekrar olasılığının daha yüksek olduğuna işaret etmektedir.

Anahtar Sözcükler $\quad: \quad \begin{aligned} & \text { Sağlık Politikası, Aşırı MR Kullanımı, Doğrudan ve Dolaylı } \\ & \text { Maliyetler, Türkiye. }\end{aligned}$

\section{Introduction}

The substantial improvement in technology that accompanies its increasing use in medical screening studies has been of great benefit in terms of patients, especially in recent years. More reliable and faster diagnosis, early facility, increased life expectancy can be listed as only a few of these benefits. However, there is a concern worldwide that screening technologies are beginning to be overused (Colla et al., 2017; Dinan et al., 2010; Hillman et al., 1990; Mafi et al., 2017; Tynan et al., 2008). The proportion of repetitive screening in the study conducted in 2007 for the United States reported to be around 20\%. These figures are reported as $4 \%$ for the Netherlands, $8 \%$ for Canada, $10 \%$ for the UK and $16 \%$ for Germany (Hendee et al., 2010: 241). However, it is quite difficult to find similar statistics for Turkey. Consequently, it is also not possible to calculate the cost of repeated screening studies. This study aims to fill this gap by examining the features of repeated MRI cases due to the low and insufficient quality of the initial MRIs using a novel data set from Hacettepe University Hospitals. This suboptimal quality refers to; movement artefacts, use of wrong scan technique or sequence, inexperienced reader and/or shortened time intervals.

Data indicates overutilization in MRI screening per MRI unit in Turkey, with 14,992 MRI images per MRI unit. This figure is almost $40 \%$ higher screening per unit ratio than its closest follower Hungary, and almost triples the OECD average. In 2016 alone, more than 12.5 million MRI examinations were performed (MOH, 2017). Turkey produces a high number of MRI examinations with a low number of MRI units. The OECD average of MRI units per million is 16.2 while this ratio in Turkey is only 10.5. Furthermore, the highest number of MRI units are in private facilities whereas the lowest number of units are in university hospitals. When screening statistics are examined for the OECD member countries, the number of MRI units and the use of MRI in screening health services are following an upward trend both for the overall group, and specifically for Turkey. There is a substantial increase from 2002 to 2014 in the utilization of screening services, suggesting that they are increasingly used for more precise diagnosis, and the charting of more appropriate care. However, it has been well documented that the dramatic increase in screening has increased the radiation exposure of patients, depending of course on the type of screening (Cascade et al., 1998: 562). Table 1 presents MRI statistics for 2016 for Turkey and the OECD average for comparison. 
Table: 1

2016 MRI Statistics

\begin{tabular}{|l|c|c|c|c|}
\hline & Number of units ${ }^{3}$ in hospitals & Unit per million patients & Number of examinations & Examination per unit \\
\hline State & 299 & 3.7 & $8,073,145$ & 27,000 \\
\hline University & 109 & 1.4 & $1,602,848$ & 14,705 \\
\hline Private & 428 & 5.4 & $2,857,676$ & 6,677 \\
\hline Total & 836 & 10.5 & $12,533,666$ & 14,992 \\
\hline OECD average & 422 & 16.2 & $1,489,744$ & 5,125 \\
\hline
\end{tabular}

Source: MoH, 2017 Statistics and OECD Health care sources statistics.

There has been a paucity of studies focusing on the identification, quantification and analysis of the repeat diagnostic problem, and in general about the effectiveness of the diagnostic machinery. (Smith et al., 2008; Sistrom et al., 2012; Lang et al., 2013). Moreover, in the case of Turkey, there is no study investigating patterns and determinants of the use of diagnostic medical screening mostly because of the unavailability of relevant data. In this context, this study aims to determine the basic factors affecting repeated MRI scans due to low quality of the initial tests performed.

We addressed the reason for high number of MRIs by a novel dataset constructed from the patient records of Hacettepe University Hospitals, one of the biggest institutions in the Turkish health system, tracking the quality of their previous MRI when the patients applied to a tertiary institution. This cross section of data was analysed with a radiology expert who analysed whether these MRI's from other institutions cleared the quality threshold or not. The results of our effectiveness analysis suggest that the effectiveness variation is still too large in the Turkish health system, that create an increase in repeat MRIs, which increase the costs of screening, without increasing the effectiveness of screening. In the discussion part, we will discuss potential policy designs to limit this burdensome weight on the Turkish health sector.

\section{Methods}

Within the scope of this study, patients who applied for MRI consultation between 01.01.2017 - 01.01.2018, for re-evaluation of the MRI scan, which was assessed in a medical facility other than Hacettepe University Hospitals, were retrospectively collected. Hacettepe University policy states that these MRI consultations were initially reviewed for its quality by a radiologist before acceptance. Very low quality MRIs and scans that have insufficient number of sequences $(\leq 1.5 \mathrm{~T})$ were not accepted for re-evaluation. Therefore, this collection of MRI consultations is only a part of the patients who applied for it. After the collection of MRI consultations, patients who had the same MRI scan repeated at the afore-mentioned time interval in the institution were investigated. Further, we have identified the reasons for

3 There were only 58 MRI units in Turkey in 2002. By 2012 this number has increased to 720 and increasing ever since. 
the repeat of the examination via the institution's data system. The patients who had repeat MRI scan because of inadequate quality of the previous scan were included in the study.

An expert radiologist re-evaluated the sufficiency of the initial MRIs from the previous medical facility. The criteria of MRI scans labelled as inadequate were as follows:

- Scans that were technically insufficient which have poor screening quality or with significant screening distortions or artefacts effecting diagnostic quality.

- Scans without sequences which must be obtained according to the clinical information (e.g. an MRI scan without post contrast images while evaluating or looking for a mass, epilepsy screening without thin slices).

The reports of MRI consultation and the repeat MRI scan, which were both reported in the institution, were reviewed for any change and noted if there is a significant change in the diagnosis or if this change is effecting the treatment. The main purpose of the study was to determine how many of the repeated MR examinations are repeated for inadequate / poor quality. The distributions of female-male and adult-child of these tests were balanced.

We have applied a univariate logistic regression in order to determine the odds ratios and hence risk factors for anatomical area, sex, age, initial screening centre and diagnosis change. Finally, we present the direct cost estimations of these repeated MRI scans.

Logistic regression essentially models the probability of the MRI scans to be repeated. In this study the dependent variable takes a value of 0 if the MRI is not repeated and 1 if repeated.

$$
y^{*}=x^{\prime} \beta+e
$$

In equation (1), $\mathrm{y}^{*}$ represents the dependent variable, $\mathrm{x}$ represents the independent variable and $\beta$ is the parameter. This study models the probability of MRI repeats, using a univariate logistic regression model following Hosmer and Lemeshow (2000).

$$
\begin{aligned}
& \operatorname{Pr} o b(Y=1 \mid x)=F(x, \beta) \\
& \operatorname{Pr} o b(Y=0 \mid x)=1-F(x, \beta)
\end{aligned}
$$

When equation (2) is exponentiated using a logistic transformation, we obtain the logistic model.

$$
\operatorname{Pr} o b(Y=1 \mid x)=\frac{e^{x^{\prime} \beta}}{1+e^{x^{\prime} \beta}}=\lambda\left(x^{\prime} \beta\right)
$$




\section{Results}

The total number of patients who were admitted to Hacettepe University Hospitals from other facilities for consultation and whose MRI examinations were repeated in the same year for any reason during the one year period was 477.162 of those repetitions was on the grounds of suboptimal image quality, evaluated by the expert radiologist using above mentioned criteria. At this stage of the study, MRIs that have not been replicated in the mentioned period were excluded. $33.96 \%$ of the MRI examinations, admitted from screening centres/hospitals other than the institution within a 1-year period were found to be poor quality and had to be repeated for diagnosis. It should also be mentioned that this $33.96 \%$ is thought to be an underestimation since several MRI scans are not even admitted at the first place by the clinician due to very low quality. Table 2 offers information regarding the anatomic area classification of the MRI scans.

Table: 2

Anatomic Area Classification

\begin{tabular}{|c|c|c|c|}
\hline & & Repeated & Total \\
\hline \multirow{2}{*}{ Abdomen } & $\mathrm{N}$ & 31 & 89 \\
\hline & $\%$ & 34.83 & 18.66 \\
\hline \multirow{2}{*}{ Head and neck } & $\mathrm{N}$ & 8 & 28 \\
\hline & $\%$ & 28.57 & 5.87 \\
\hline \multirow{2}{*}{ Muscle and skeleton } & $\mathrm{N}$ & 15 & 65 \\
\hline & $\%$ & 23.08 & 13.63 \\
\hline \multirow{2}{*}{ Neurology } & $\mathrm{N}$ & 93 & 261 \\
\hline & $\%$ & 35.63 & 54.72 \\
\hline \multirow{2}{*}{ Spinal } & $\mathrm{N}$ & 14 & 31 \\
\hline & $\%$ & 45.16 & 6.50 \\
\hline \multirow{2}{*}{ Thorax } & $\mathrm{N}$ & 0 & 3 \\
\hline & $\%$ & 0 & 0.63 \\
\hline Total & $\mathrm{N}$ & 161 & 477 \\
\hline
\end{tabular}

Data indicates that the highest repeat ratios are found in spinal MRI scans. Out of 14 scans within a total of 31 was repeated within the observation period yielding a repeat rate of $45.16 \%$, followed by neurology, abdomen and head and neck.

We found no significant difference in the odds ratios in terms of anatomic area classification. However, the results indicate an increased risk of MRI scan repeat for women and children (Table 3).

Table: 3

Prevalence and OR for Sex and Age

\begin{tabular}{|l|c|c|c|}
\hline Sex & $\mathbf{N}$ & \% & OR \\
\hline Male & 228 & 47.80 & 1.00 \\
\hline Female & 249 & 52.20 & $1.52^{* *}$ \\
\hline Total & 477 & 100 & \\
\hline Age & $\mathbf{N}$ & 48.64 & OR \\
\hline Child & 232 & 51.36 & 1.00 \\
\hline Adult & 245 & 100 & $0.69^{* *}$ \\
\hline Total & 477 & & \\
\hline
\end{tabular}

Table 3 shows that the likelihood of recurrence is significantly greater in women and children because MRIs were considered to be insufficient. 
Further, we investigated where the MRIs have been taken and whether there are any diagnostic differences among the MRIs taken for consultation and the MRIs taken at the institution. Table 4 provides information on the MRIs from other centres.

Table: 4

Origin of the Consulted MRI

\begin{tabular}{|l|c|c|}
\hline & Total & $\%$ \\
\hline Private Screening Centre /Hospital & 40 & 24.69 \\
\hline Private University Hospital & 4 & 2.46 \\
\hline State Hospital & 46 & 28.39 \\
\hline State University Hospital & 63 & 38.88 \\
\hline N/A & 9 & 5.55 \\
\hline Total & 162 & 100 \\
\hline
\end{tabular}

109 repetitions of 162 examinations were brought in from state hospitals or universities whereas 44 of them were brought in from private screening centres, private hospitals or private universities. $29.62 \%$ of the MRIs that were repeated within the institution resulted in a change in the initial diagnosis and hence management of the patient.

When examining the cases in which repeated examinations were drawn, the majority of the first examinations were from Ankara with a ratio of $34.48 \%$. Diyarbakir and Konya follows with $6.21 \%$ and $4.14 \%$ respectively. 20 out of 50 MR examinations brought from the centres in Ankara for consultation to the institution were sourced from the private centre and the percentage of diagnosis changes in MRIs from private centres is lower than in statebased MRIs (33.94\% for state and $25 \%$ for private).

\section{Conclusion}

When we look at pattern of change in MRIs in Turkey, we observe a tripling in the total national aggregate numbers. This concerning issue is also within the agenda of policy makers. In this study, we first tried to disaggregate the use of MRIs using the classification to differentiate whether the increase is due to the intensive use (a more widespread use of the already existing machines) or changes in extensive use of MRI machines (where new machines are added to the national registry). We observe that especially in the post 2010 period the increase in MRI is mostly through intensive (already existing machines being used more than before) rather than extensive (more machines being put into use than before) increases, which suggests we need to focus on how the already existing machinery in this field is being used. On the other hand, the regional variation for the MRI machine use has decreased, suggesting that machines are increasingly being used in geographies that it did not exist in before. However, in the presence of potential quality variation in machines and variation in the quality of staff that is operating these machines, the crucial question becomes; is this increased MRI use effective? Effectiveness and repeat use literature suggests that, in order to understand the cost and use of MRI's one needs to understand which population group drives the MRI increase and repetition, and also which anatomical area, and what portion of the increase comes from over-repetition (Smith-Bindman et al., 2008). 
The findings of the study indicate a serious problem. Even though the scope of the study can be considered narrow in terms of period, examination and location, the results obtained are quite striking. Within one year, Hacettepe Universtiy hospitals repeat MRIs in $34 \%$ of the cases due to the insufficient quality of the preceding MRI. It is clear that this ratio is an underestimation since the lowest quality MRIs are not taken in even for consultation and that the repetition rates are probably much higher across the country.

Even in terms of the explicit costs of repetition, the results suggest a sizeable effect on the individual and public budgets in terms of repeated screening. Turkish government reimburses all state and university hospitals and some private hospitals around $\$ 10^{4}$ per MRI. Using the current cost figures that have been announced by the Turkish Health Ministry, even the situation in Hacettepe University Hospitals as a single centre results in an excess and avoidable cost of $\$ 1676^{5}$, just due to the insufficient quality of the MRI's arriving from other health institutions. These MRIs are repeated since the expert judges them insufficient for a correct assessment and diagnosis.

The main problem with these repetitions is suboptimal quality. Several reasons can be listed for repetition of radiologic diagnostics. In this study, as mentioned before, we are only focusing at repetition of MRI's.

Health system design and health policy itself can be seen as the main factor attributing to overutilization of MRI's. Turkish Health System can be identified as pro-patient. More than $95 \%$ of individuals have health insurance and equitable access to health care services (Başar et al., 2018). Patients do not pay any extra fees for MRI examinations at state hospitals or at state university hospitals. The fee differs in private hospitals and screening facilities. Furthermore, the Turkish health care system allows for self-referral of patients to any physician and health care facility. In addition, physicians do not have access to health records of patients from other health facilities. Therefore, other than declaration of the patient, the physician does not have any knowledge of prior examinations in different health facilities. Finally, the performance based payment system is an important factor influencing overutilization. Due to the high number of patients it is possible to observe shorter examination periods but more laboratory and screening to save time. Hence, we can suggest that the Turkish health system facilitates overutilization as well.

Furthermore, similar to the European and US health systems, medical malpractice claims have dramatically increased in Turkey (Ozmen et al., 2015; Eş et al., 2017; Arıkan et al., 2017). Increases in medical malpractice claims inevitably surge the concept of defensive medicine and hence facilitate overutilization of screening techniques (Hendee et al., 2010). Increases in malpractice claims inevitably exacerbate the practice of defensive medicine and 
hence facilitate overutilization of screening techniques (Hendee et al., 2010). Although the scale and economic size of the industry created by the medical malpractice laws and legal structures does not compare to its US counterpart (Mello et al., 2003; Bilimoria et al., 2017), the Turkish malpractice laws have been increasing in scope and effectiveness in the $21 \mathrm{st}$ century.

The two significant changes to malpractice law has occurred in 2004, and 2012, with no additional legal changes expected in the near future. Since then, there has been a growing literature on the effect of malpractice law in Turkey on different specialties and different physician sub groups (Arıkan et al., 2017; Solaroğlu et al., 2014; Küçük, 2018). The results suggest a significant effect on physician behavior, with a significant move toward more defensive medicine in all of the subsamples. Our research, however, focuses more on documenting the size of the over-repetition in the screening industry, where the malpractice issues will be relatively unimportant.

Physicians and radiologists can also contribute to the overutilization of medical screening. It is common for the referring physician to request a rectification of lack of information about the details of a certain workup rather than choosing alternative procedures with lower direct and indirect costs. Furthermore, the radiologist may lack information about the most suitable screening technique. Our study reveals that, most suboptimal results are due to lack of technique -especially in abdomen MRI's-, lack of contrast matter or suboptimal sequencing.

Several methods have been offered worldwide to decrease overutilization of medical screening such as a computerized decision support system, accreditation of screening facilities and educating the referring physicians and radiologists (Armao et al., 2012). However, overutilization is still an important subject and focus of interest.

In terms of the indirect costs of misapplying the diagnostic technologies: misplaced diagnosis, inappropriate care, wrong medication, wrong technology use, and wasted personhours of doctors and nurses and health personnel are indeed the significant factors that increase these health costs. Our results suggest that these problems could also be significant just like the size of the explicit costs. The problem of misdiagnosis because of suboptimal screening technologies creates an excess cost of repeated screening in an attempt to correct the mistake. The misdiagnosis problem may be clustered in the higher stages of the health system, where the misdiagnosis is identified, but the higher stages of the health system is associated with higher labour costs, and higher treatment costs. In other words, there are also indirect (or implicit) costs of repeated screening which cannot be quantified in this study due to data limitations. However, it is clear that the total cost of repeated screening would be much higher when indirect costs can be included in the analysis. Notwithstanding this limitation, analysis of patterns of diagnostic medical screening and repeated screening via MRI can be seen as a first step in terms of estimation of its economic consequences for Turkey. In this regard, it can be argued that this study is the first attempt to investigate the basic characteristics of repeated MRI examinations resulting from low quality by employing data collected from Hacettepe University Hospitals. 
Başar, D. \& İ.C. Özen \& S. Öztürk \& E. Gümeler \& D. Akata \& A.Ö. Çiftçi (2019), "The Case of MRI Repetitions with Direct and Indirect Cost Implications: Evidence from Hacettepe University Hospitals”, Sosyoekonomi, Vol. 27(41), $253-262$.

Since the most important limitation for this study is data unavailability, for future research, focusing on repeated screening over time would provide more information regarding the trend. Future studies might also investigate the total cost of repeated screening considering both direct costs and indirect costs (e.g. lost working time and earning) if the relevant data becomes available. Finally, even though this study is not nationally representative we believe that it is an important first step and an original subject matter especially for Turkey.

Our results suggest that in the next stage of the development of the Turkish health system, after the increased use of screening technology in the earlier stage, a more integrated and coordinated approach can be designed so that the quality variation in the output dimension of the screening technologies is minimized. Further, the incentive schemes should be targeted towards the correct and applicable use of screening technologies that brings forth a more correct diagnosis together with a better health care to a larger part of the Turkish geography.

\section{References}

Arıkan, A. \& S. Çınarlı \& F.Ş. Aykar \& A. Sayan (2017), “Attitudes of Medical Malpractice in Pediatric Surgery", The Journal of Pediatric Research, 4(3), 117.

Armao, D. \& R.C. Semelka \& J. Elias Jr (2012), "Radiology's ethical responsibility for healthcare reform: tempering the overutilization of medical screening and trimming down a heavyweight", Journal of magnetic resonance screening, 35(3), 512-517.

Başar, D. \& S. Öztürk \& İ. Cakmak (2018), “An Application of the Behavioral Model to the Utilization of Health Care Services in Turkey: A Focus on Equity", Panoeconomicus, Advance online publication, 1-22.

Bilimoria, K.Y. \& J.W. Chung \& C.A. Minami \& M.W. Sohn \& E.S. Pavey \& J.L. Holl \& M.M. Mello (2017), "Relationship between state malpractice environment and quality of health care in the United States", The Joint Commission Journal on Quality and Patient Safety, 43(5), 241-250.

Cascade, P.N. \& E.W. Webster \& E.A. Kazerooni (1998), "Ineffective use of radiology: the hidden cost”, AJR. American journal of roentgenology, 170(3), 561-564.

Colla, C.H. \& A.J. Mainor \& C. Hargreaves \& T. Sequist \& N. Morden (2017), "Interventions aimed at reducing use of low-value health services: a systematic review", Medical Care Research and Review, 74(5), 507-550.

Dinan, M.A. \& L.H. Curtis \& B.G. Hammill \& E.F. Patz \& A.P. Abernethy \& A.M. Shea \& K.A. Schulman (2010), "Changes in the use and costs of diagnostic screening among Medicare beneficiaries with cancer, 1999-2006”, Jama, 303(16), 1625-1631.

Eş, H. \& Y. Özer \& Z. Liman \& A. Şanlı (2017), "General surgery malpractice claims in Turkey”, Romanian Journal of Legal Medicine, (2), 272-278.

Hendee, W.R. \& G.J. Becker \& J.P. Borgstede \& J. Bosma \& W.J. Casarella \& B.A. Erickson \& P.E. Wallner (2010), “Addressing overutilization in medical screening”, Radiology, 257(1), 240-245.

Hillman, B.J. \& C.A. Joseph \& M.R. Mabry \& J.H. Sunshine \& S.D. Kennedy \& M. Noether (1990), "Frequency and costs of diagnostic screening in office practice-a comparison of self- 
referring and radiologist-referring physicians", New England Journal of Medicine, 323(23), 1604-1608.

Hosmer, D.W. \& S. Lemeshow (2000), Applied Logistic Regression, John Wiley \& Sons.

Küçük, M. (2018), "Defensive medicine among obstetricians and gynaecologists in Turkey”, Journal of Obstetrics and Gynaecology, 38(2), 200-205.

Lang, K. \& H. Huang \& D.W. Lee \& V. Federico \& J. Menzin (2013), "National trends in advanced outpatient diagnostic screening utilization: an analysis of the medical expenditure panel survey, 2000-2009”, BMC Medical Screening, 13(1), 40.

Mafi, J.N. \& K. Russell \& B.A. Bortz \& M. Dachary \& W.A. Hazel Jr \& A.M. Fendrick (2017), "Low-cost, high-volume health services contribute the most to unnecessary health spending”, Health Affairs, 36(10), 1701-1704.

Mello, M.M. \& D.M. Studdert \& T.A. Brennan (2003), “The new medical malpractice crisis”, New England Journal of Medicine, 348(23), 2281-2284.

Ozmen, P. \& S. Sahin \& M. Cetin \& Y.Z. Turk (2015), “A Medical Malpractice Research Conducted in Turkey, Causes and the Role of Media", Journal of Archives in Military Medicine, $3(2)$.

Sistrom, C. \& N.L. McKay \& J.B. Weilburg \& S.J. Atlas \& T.G. Ferris (2012), "Determinants of diagnostic screening utilization in primary care", The American journal of managed care, 18(4), e135-44.

Smith-Bindman, R. \& D.L. Miglioretti \& E.B. Larson (2008), "Rising use of diagnostic medical screening in a large integrated health system", Health Affairs, 27(6), 1491-1502.

Solaroglu, I. \& Y. Izci \& H.G. Yeter \& M.M. Metin \& G.E. Keles (2014), "Health transformation project and defensive medicine practice among neurosurgeons in Turkey", PloS one, 9(10), e111446.

TCSB SAGM (2017), Să̆lık İstatistikleri Yıllı̆̆g 2016, Ankara.

Tynan, A. \& R.A. Berenson \& J.B. Christianson (2008), "Health plans target advanced screening services: cost, quality and safety concerns prompt renewed oversight", Issue Brief (Center for Studying Health System Change), (118), 1-4. 